\title{
A SOCIODENTAL APPROACH IN PROSTHODONTIC TREATMENT DECISION MAKING
}

\author{
UMA ABORDAGEM SOCIAL NAS TOMADAS DE DECISÃO NO \\ TRATAMENTO COM PRÓTESE DENTÁRIA
}

Cláudio Rodrigues LELES ${ }^{1}$, Maria do Carmo Matias FREIRE²

1- Professor, Dept, of Prevention and Oral Rehabilitation, Federal University of Goiás.
2- Professor, Dept. of Stomatological Sciences, Federal University of Goiás.

Corresponding address: Prof. Cláudio R. Leles - Faculdade de Odontologia da UFG - Praça Universitária, s/n, Setor Universitário, CEP 74.605-220 - Goiânia-GO - Phone.: (62) 209-6250 - e-mail: crleles@odonto.ufg.br

Received: November 24, 2003 - Accepted: February 16, 2004

\begin{abstract}
A

critical problem in the decision making process for dental prosthodontic treatment is the lack of reliable clinical parameters. This review discusses the limits of traditional normative treatment and presents guidelines for clinical decision making. There is a need to incorporate a sociodental approach to help determine patient's needs. Adoption of the evidence-based clinical practice model is also needed to assure safe and effective clinical practice in prosthetic dentistry.
\end{abstract}

UNITERMS: Dental prosthesis; Treatment needs; Decision-making; Sociodental approach.

\section{RESUMO}

$\bigcup_{\mathrm{m}}$ problema crítico no processo de tomadas de decisão em prótese dentária é a falta de parâmetros clínicos confiáveis nas condutas clínicas de tratamento. A presente revisão descreve e discute alguns aspectos desse problema e apresenta diretrizes para as decisões clínicas a partir do levantamento de limitações inerentes ao tratamento normativo tradicional. Conclui-se que há necessidade de incorporação de uma abordagem sócio-odontológica na determinação de necessidades dos pacientes. A adoção de um modelo de práticas baseadas em evidências é essencial para assegurar práticas clínicas seguras e efetivas em prótese dentária.

UNITERMOS: Prótese dentária; Necessidade de tratamento; Tomada de decisão; Abordagem sócio-odontológica.

\section{INTRODUCTION}

Prosthodontic rehabilitation of partially or completely edentulous patients is important in clinical practice, since the definitive treatment can improve oral function, esthetics and quality of life of most patients. Despite the great decline in dental caries and tooth loss in the last decades, it is believed that there will be an increased demand for prosthodontic care in the future ${ }^{10}$.

It is reasonable to consider that not all patients with tooth loss need prosthodontic care. Recent evidence suggests that a missing tooth does not imply need for dental treatment ${ }^{23}$. Although prosthetic replacement of any missing tooth seems unequivocal from the clinicians' point of view, deciding a patient's prosthetic needs is definitely not a simple task.
Traditionally, determination of prosthodontic treatment options and selection of treatment have been considered part of the practitioner's professional responsibility. In contemporary clinical practice, patients are increasingly assuming an active role in determining their actual treatment needs, by stating their expectations and desires. Similarly, new professional requirements derived from the evidencebased practice model demand clinical approaches that are effective and safe.

Inconsistencies among clinicians' treatment decisions have a financial impact and ultimately can affect clinical viability of the treatment outcome ${ }^{28}$. Therefore, an improvement in professional ability to identify patients reasons for intervention is required for a better clinical practice $^{3,6}$. Problems observed in clinical practice such as different approaches to treat similar situations and failures 
in evaluating risk factors can lead to ethical problems and litigation. This is particularly important when intervention decisions are made.

The aim of this review is to discuss a set of social and individual factors that influence determination of treatment needs in order to substantiate a sociodental approach and evidence-based decision making process in prosthetic dentistry.

\section{Decision making problems in prosthodontics}

Factors that influence need and demand for prosthetic treatment are not properly recognized and seldom considered by dentists. Additionally, variations in clinical decisions are almost ubiquitous ${ }^{3,5}$, and efficacy, effectiveness and costbenefit parameters are important aspects of intervention that are poorly understood in restorative dentistry ${ }^{4}$. Prosthetic treatment is not uniquely limited to technical aspects. Indeed, it includes multidimensional aspects of patient perceived needs, desires and expectations ${ }^{7,23}$. When these aspects are neglected, a conflict between the amount and extent of treatment dentists believe patients should receive and what patients themselves perceive as treatment need is frequently observed ${ }^{9}$. Patients usually tend to be more positive regarding their oral health. This subjective perception by patients is relevant and professionals should change from making unilateral decisions, and consider the patients' point of view before any treatment decision is made $^{9,14,23}$.

This is not, however, a usual practice in dentistry since clinical decisions bears very little relationship to rational decision making ${ }^{25}$. Patients have little influence in treatment prescription made by experienced professionals to whom technical aspects outweigh patient-related factors. ${ }^{16,19}$ Moreover, traditional clinical practice greatly emphasizes and overestimates technical solutions to oral health problems. Treating diseases after they have occurred is frequently ineffective, iatrogenic, palliative and high-cost ${ }^{24}$. None of these interventions are directed at the cause of the problem or centered on preventive strategies. On the contrary, the customary option towards complex and irreversible techniques is not sufficient to permanently limit structural damage or reduce future risks of disease, and greatly increases the risk of overtreatment and other iatrogenic outcomes.

Another facet of this problem is the limited survival of prosthetic treatment and risks associated to its clinical performance ${ }^{2}$. Rigid clinical protocols that reinforce the importance of follow-up and rigorous maintenance of treatment can be considered a clear evidence of the transitory nature of restorative prosthetic solutions. According to Sheiham ${ }^{24}$, "the question is not will they go bad, it is when. So they monitor constantly". This is particularly true when invasive conventional treatment is provided, but certainly not necessary for osseointegrated implants when clinical favorable conditions are present.

The unique restorative approach does not seem to be always necessary. It is quite ineffective and inefficient to control oral diseases and tooth loss, and it is usually too costly and at best, palliative ${ }^{25}$. In contrast, an approach directed towards limitation of restorative interventions to the minimum necessary may be considered the standard approach in prosthodontic treatment ${ }^{8}$. Studies in patients with shortened dental arches (limited to four occluding pairs of premolars) have demonstrated that masticatory function, comfort and occlusal stability can be satisfactory to fulfill patients' needs, specially in older adults ${ }^{30}$.

Additionally, the traditional view that an incomplete dentition invariably results in functional deficits and dysfunctional disorders of the masticatory system has been seriously questioned ${ }^{30}$. A reduced dentition (less than 28 teeth) can accomplish functional needs, and the demand for prosthetic replacement is deeply associated to the position of the lost teeth. For example, in the majority of patients, esthetics (related to the presence of anterior teeth) is far more important than function (related to the presence of posterior teeth) ${ }^{14}$. There is a positive correlation between tooth position and patient satisfaction with the mouth. The presence of an intact anterior sextant and at least three premolars in occlusion are the best predictors of satisfaction ${ }^{14}$.

In contrast, the consequences of not replacing a missing tooth, traditionally viewed as a compromise to occlusal function and stability ${ }^{20}$, are less hazardous than once thought $^{15}$. Movement of teeth adjacent to posterior edentulous spaces is usually gradual and minor ${ }^{15,26}$, even when considered in a long-term perspective ${ }^{18}$. Shortened edentulous areas bound by natural dentition do not lead to inevitable arch collapse resulting from the movement of adjacent teeth and immediate prosthodontic replacement is not critical for occlusal stability and periodontal health ${ }^{26}$. The survival of teeth adjacent to untreated posterior bounded edentulous spaces is not positively influenced by conventional prosthodontic treatment, especially when a removable partial denture is the treatment option ${ }^{2,27}$. On the other hand, additional information is needed to substantiate non-intervention in patients with large edentulous areas.

The fundamentals of decision making in prosthetic dentistry should be carefully analyzed. The current interventionist model has serious shortcomings. A costeffective and successful treatment requires a change from the widespread beliefs of technological-restorative dental care towards clear strategies for health promotion ${ }^{24}$.

Dentists traditionally have a normative view of prosthetic treatment planning, assuming almost exclusively the responsibility of addressing treatment decisions. Consequently, a mismatch may exist between patients' desires and expectations and the actual treatment provided by the dentist. Even when patients include their personal preferences or financial condition in the treatment planning, other relevant factors are rarely considered such as the impact of these decisions on quality of life, the readiness of updated scientific evidence of intervention efficacy, and the likelihood of a successful long-term outcome.

Normative systems for determination of prosthetic treatment needs usually disregard social aspects. Little or 
no value is given to how oral condition affect patients' daily life or if the patients can change behavior to facilitate a real health gain. Instead, determination of need for prosthetic intervention is mainly, and sometimes only, defined by the absence of the teeth or the extent to which patient's occlusion deviates from an arbitrary norm ${ }^{23}$. These criteria are generally dictated by professional preference or convenience and may result in problems in treatment outcome.

\section{A sociodental approach of dental needs in prosthodontics}

The normative approach is primarily guided by the acessed clinical health state assessed or physical impairment, while the sociodental approach is multidimensional and involves a strategic mediation of several aspects of patient's perceived need and potential risks and benefits of intervention. In cases of prosthodontic treatment of an edentulous posterior space (tooth bounded or shortened dental arch), an obvious conflict is generated from these two perspectives, as shown in Table 1.

Assessment of perceived need in sociodental approach is focused on problem-solving ${ }^{30}$. Tooth loss (structural impairment) can, but not necessarily, lead to food avoidance or reduced nutritional intake (functional limitation), or result in emotional distress, social or professional deprivation (psychological discomfort). If the dentist is not prepared to properly identify these needs, clinical decisions are based on idiosyncratic choices that often lead to overtreatment. Previous studies confirmed that clinical decisions that involve restorative treatment are frequently variable, conflicting and poorly defined ${ }^{22}$.

Overtreatment and increasing complexity of treatment are common aspects of normative approach. Great differences in estimated need of prosthetic treatment in elderly patients were observed when comparing normative and sociodental approaches ${ }^{29}$. Special attention should be paid to extensive and aggressive restorative approaches, which may be unnecessary or inappropriate ${ }^{13}$. When financial restrictions are mandatory, decisions based on social determinants are clearly more rational, cost-effective and safe, since priority is given to conservative, less invasive and less expensive solutions. Inequality of access to effective dental care is also reduced.

Minimal intervention prosthodontics can be considered a treatment option for a country's overall dental health care plan, mainly in developing countries that are under significant pressure to effectively utilize limited resources, to increase skilled human resources, and to provide advanced levels of care to very large number of patients ${ }^{8}$.

An exclusive normative approach should only be used when a patient's condition is potentially life threatening or when progressive derangement is identified, like active

TABLE 1- A normative (traditional) approach versus a sociodental approach in prosthetic treatment

\begin{tabular}{lll}
\hline & \multicolumn{1}{c}{ Normative } & Sociodental \\
\hline Determination of & $\begin{array}{ll}\text { Based on morphological criteria: } \\
\text { treatment need }\end{array}$ & $\begin{array}{l}\text { Based on patient's perceived need in addition to normative } \\
\text { assessment } \\
\text { that does not fulfill an arbitrary }\end{array}$ \\
& & \\
& & \\
& & \\
\hline
\end{tabular}

Aims of treatment Addressed to physical Addressed to a problem-solving treatment plan and
impairment and restoration of restoration or preservation of functional dental arches complete dental arches

$\begin{array}{ll}\text { Previous assumptions } & \text { Tooth loss is potentially harmful } \\ \text { for intervention or } & \text { to arch stability, chewing } \\ \text { non-intervention } & \text { efficiency and functional balance } \\ & \text { of the masticatory system. }\end{array}$

Basis for intervention
Considers clinical and technical aspects like:

- Professional expertise and priorities

. Financial situation of the patient
Considers multidimensional aspects like:

- Potential individual risks of intervention or non-intervention

- Proven efficacy of treatment

- Cost-benefit relation in terms of health gain

- Patient's propensity to maintain a positive health behavior after treatment 
caries, or when a future rehabilitation can be unfeasible. In such cases, immediate intervention is obligatory.

Another pitfall of prosthodontic normative care is the lack of available reliable clinical evidence of the efficacy of interventions. Clinical performance of materials and restorative techniques is poorly known and primary based on anecdotal information. A large part of past prosthetic literature is not evidence-based and a diversity of treatments is justified only on the basis of weak case series and case report designs ${ }^{1}$. Additionally, properly conducted randomized controlled clinical trials, which provide the most reliable basis for evaluating the effectiveness of treatment interventions, are scarce and commonly subject to bias ${ }^{11,12}$.

\section{The clinical application of a sociodental approach in prosthodontics}

The majority of studies about clinical decision making process do not refer to prosthetic treatment. However, similar clinical questions are present in prosthetic care as in other areas of dentistry or medical care. These questions focus on specific clinical decisions like "when to intervene or not intervene?”, "what should be the level of intervention?”, "what materials and techniques should be chosen?", "what are the potential risks and expected benefits of the proposed treatment?”.

In many instances, the final treatment decision is a function of what therapy options are offered to the patient (provider's preference), and which treatment the patient finds most appealing (consumer's preference) in respect to cost, esthetic improvement and treatment complexity ${ }^{17}$. This simplistic view produces a limited understanding of treatment outcome. A broader measure of appropriateness of treatment approaches may encompass a determination of the level of intervention. Prosthetic care, as a rule, allows multiple treatment choices. Therefore, clinical decision may vary from a very extensive intervention to a very limited one (or even no intervention $)^{7}$. Multidimensional aspects of needs assessment and determination, that involves both the clinician and the patient, may guide clinical decisions, and can be summarized as follows and in Table 2:

1. Patient's chief complaint: assessment of present dental status, self-perceived needs and susceptibilities, priorities for care, perception of symptoms, and feelings of threat of disease, as well as professional's identification and judicious assessment of normative needs.

2. Patient's desires and expectations: assessment of patient's expected outcomes and patient's beliefs about potential risks and benefits of treatment.

3. Patient's preferences: evaluation of patient's previous concepts and beliefs about prosthetic alternatives, and attitudes in response to proposed treatment plans; if necessary, unrealistic thoughts may be changed by a through professional orientation.

4. Impact of intervention on patient's quality of life: evaluation of the potential influence of treatment on daily activities and interference with social environment.

5. The likelihood of a favorable prognosis for the individual patient: the probability of success and long-term survival of treatment.

6. Patient's ability in maintaining a healthy oral condition after treatment: involves individual's potential for increased dental health care, promoted and supported by appropriate dental health education ${ }^{21}$.

7. Viability of other treatment alternatives: assessment of effectiveness and safety of different intervention approaches.

8. Patient's capacity to handle the stress associated to all stages of treatment, mainly associated with extensive and invasive approaches.

9. The availability of financial resources, manpower, technical support, and professional's skills to perform the proposed treatment plan (in some cases referral is advised).

These determinant factors should always be considered as playing an important role in a successful prognosis. More aggressive care levels may be selected only if a strong supporting rationale takes into account these determinants in diagnosis and treatment planning?.

A comprehensive evaluation of these issues may lead to the choice of "the best possible therapy" for the individual patient, and practical clinical guidelines can be recommended in order to improve consistency among clinical providers of prosthetic care (Table 3).

TABLE 2- Practitioners' checklist of multidimensional aspects of prosthetic needs assessment and treatment decisions (see details in text)

1. Determine patient's chief complaint

2. Evaluate patient's desires and expectations

3. Identify patient's preferences

4. Explore the possible impact of intervention on patient's quality of life

5. Assess the likelihood of a favorable prognosis for the individual patient

6. Evaluate patient's ability in maintaining a healthy oral condition after treatment

7. Evaluate the realistic viability of other treatment alternatives

8. Patient's ability to cope with the stress of selected treatment

9. Check the availability of financial resources, manpower, technical support and professional skills 


\section{FUTURE NEEDS}

Definite evidence supporting different prosthodontic treatment options are lacking. If many clinical decisions rely on professional experience and clinical skills, inherent confounding factors like uncertainty, errors, and divergence of opinions, motives and personal values weaken the link between the patient's actual condition and the appropriate selection of treatment. Many of these uncertainties demand efforts toward and focusing decisions on evidence-based practice. This implies a shift from the traditional paradigm that overemphasizes technological solutions in favor of strategies for health promotion. A reasonable search and use of best external scientific evidence must include a clear definition of the clinical problem, a systematic search for high quality evidence in the literature, critical judgment to decide the validity and appropriateness of the available evidences and a continuing critical appraisal of the clinical practice routine.

Patients and insurers demand assurance of treatment effectiveness. Currently, information is freely and easily available to patients and, as a result, litigation is increasing. Furthermore, misuse of financial and skilled human resources is no longer acceptable. Decisions guided by a sociodental approach comply with these new demands of health care, avoiding overtreatment and the questionable efficacy, effectiveness, and cost-benefit of traditional clinical practice.

\section{CONCLUSIONS}

Despite the limitations of existing knowledge and the need for further research, the following conclusions can be drawn regarding sociodental approach in prosthetic treatment decision making:

1. Traditional normative measures of need usually fail to accurately assess prosthetic treatment need for an individual patient.

2. The incorporation of a sociodental approach to decision making process is essential to accomplish a contemporary comprehensive prosthetic treatment planning.

3. There is limited information about the actual

TABLE 3- Guidelines for determination of the level of prosthetic treatment need (adapted from Berkey et al. ${ }^{7}$ )

Intervention level Indicated for patients... Nature of intervention

Very extensive

...with urgent prosthetic needs (functional or pathological or esthetic), and that can withstand extensive invasive treatments with a positive prognosis. Only strongly positive factors justify this level of intervention.
Extensive and complex fixed prosthodontics, associated or not to surgical procedures (including advanced surgery for implants).
Extensive

ntermediary
... with substantial needs (functional, pathologic or esthetic), adequate financial condition, and ability to tolerate stress associated to invasive and extensive treatments.
Moderate extensive fixed prostheses, associated or not to surgical interventions, and treatments involving advanced removable prostheses.
... that require some extensive intervention, as benefit is adjusted for risk (like caries risk or periodontal disease).
Basic treatment involving removable or fixed prostheses and basic surgical procedures. Professional may be challenged to develop creative alternatives to more extensive traditional treatments.
Limited ... with financial constraints, limited ability to handle with stress or experiencing a significant decline in health status. Projected risks of traditional intervention restrict potential benefits.
Extensive treatments may be inappropriate. Treatment approach should only be sufficient to minimize future dental problems.
Very limited
... with extremely limited resources. Most traditional interventions that pose a serious risk or limited outcomes are very questionable.
Minimal and low-stress interventions or even not to perform any invasive treatment. 
adequacy, safety, efficacy and effectiveness of most of prosthetic interventions.

4. There is a noticeable need for a widespread adoption of evidence-based clinical practice in prosthetic dentistry.

\section{REFERENCES}

1- Anderson J. Need for evidence-based practice in prosthodontics. J Prosthet Dent 2000; 83:58-65.

2- Aquilino A, Shugars D, Bader J, White S. Ten-year survival rates of teeth adjacent to treated and untreated posterior bounded edentulous spaces. J Prosthet Dent 2001;85:455-60.

3- Bader J, Shugars D. Descriptive models of restorative treatment decisions. J Publ Health Dent 1998; 58:210-9.

4- Bader J, Shugars D. Understanding dentists' restorative treatment decisions. J Publ Health Dent 1992;52:102-10.

5- Bader J, Shugars D. Variations in dentists' clinical decisions. J Publ Health Dent 1995;55:181-8.

6- Bader J, White A, Olsen O, Shugars D. Dentist reliability in classifying disease risk and reason for treatment. J Publ Health Dent 1999;59:158-61.

7- Berkey D, Berg R, Ettinger R, Mersel A, Mann J. The old-old dental patient. The challenge of clinical decision-making. J Am Dent Assoc 1996;127:321-32.

8- Bowley J. Minimal intervention prosthodontics: current knowledge and societal implications. Med Princ Pract 2002; 11(Suppl 1):22-31.

9- Davenport J, Basker R, Heath J, Ralph J, Glantz P. Removable partial dentures. 1. Need and demand for treatment. Br Dent J 2000;189:364-8.

10- Douglas C, Watson A. Future needs for fixed and removable partial dentures in the United States. J Prosthet Dent 2002; 87:914.

11- Dumbrigue H, Jones J, Esquivel J. Control of bias in randomized controlled trials published in prosthodontic journals. J Prosthet Dent 2001;86:592-6.

12- Dumbrigue H, Jones J, Esquivel J. Developing a register for randomized controlled trials in prosthodontics: result of a search from prosthodontic journals published in the United States. J Prosthet Dent 1999;82:699-703.

13- Elderton R. Treating restorative dentistry to health. Br Dent J 1996;181:220-5.

14- Elias A, Sheiham A. The relationship between satisfaction with mouth and number and position of teeth. J Oral Rehabil 1998;25:649-61.

15- Gragg K, Shugars D, Bader J, Elter J, White B. Movement of teeth adjacent to posterior bounded edentulous spaces. J Dent Res 2001; 80: 2021-4.
16- Grembowski D, Milgrom P, Fiset L. Factors influencing dental decision making. J Publ Health Dent 1988; 48:159-67.

17- Jacob R, Carr A. Hierarchy of research design used to categorize the "strength of evidence" in answering clinical dental questions. J Prosthet Dent 2000;83:137-52.

18- Kiliaridis S, Lyka I, Friede H, Carlsson G, Ahlqwist M. Vertical position, rotation, and tipping of molars without antagonists. Int J Prosthodont 2000;13:480-6.

19- Kronström M, Palmqvist S, Söderfeldt B, Carlsson G. Dentistrelated factors influencing the amount of prosthodontic treatment provided. Community Dent Oral Epidemiol 2000;28:185-94.

20- Lyka I, Carlsson G, Wedel A, Kiliaridis S. Dentists’ perception of risks for molars without antagonists. A questionnaire study of dentists in Sweden. Swed Dent J 2001;25:67-73.

21- Maizels J, Maizels A, Sheiham A. Sociodental approach to the identification of dental treatment-need groups. Community Dent Oral Epidemiol 1993;21:340-6.

22- Nuttall N, Elderton R. The nature of restorative dental treatment decisions. Br Dent J 1983;154:363-5.

23- Rich G, Goldstein B. New paradigms in prosthodontic treatment planning: A literature review. J Prosthet Dent 2002;88:208-14.

24- Sheiham A. Strategies for promoting oral health care. Braz J Publ Health Dent 2001;2:7-4.

25- Sheiham A. Minimal intervention in dental care. Med Princ Pract 2002; 11(Suppl.1):2-6.

26- Shugars D, Bader J, Phillips Jr W, White A, Brantley F. The consequences of not replacing a missing posterior tooth. J Am Dent Assoc 2000; 131:1317-23.

27- Shugars D, Bader J, White A, Scurria M, Hayden Jr W, Garcia R. Survival rates of teeth adjacent to treated and untreated posterior bounded edentulous spaces. J Am Dent Assoc 1998;129:1089-95.

28- Shugars D, Bader J. Cost implications of differences in dentists' restorative treatment decisions. J Publ Health Dent 1996; 56:21922.

29- Srisilapanan P, Sheiham A. Assessing the difference between sociodental and normative approaches to assessing prosthetic dental treatment needs in dentate older people. Gerodontology 2001;18:25-34.

30- Witter D, Helderman W, Creugers N, Käyser A. The shortened dental arch concept and its implications for oral health care. Community Dent Oral Epidemiol 1999;27:249-58. 